give patients with disciform keratitis diagnostic tuberculin injections and see if a local reaction is produced. The result will aid us to determine whether this affection is or is not due to infection with tubercle bacilli. Hypopyon and deep ulceration are extremely uncommon, and when they occur must be due to added infection by some other micro-organism.

\section{THE EFFECT ON THE KIDNEY OF URETEROVESICAL ANASTOMOSIS}

EXPERIMENTAL AND CLINICAL REPORT*

\section{ANDERS PETERSON, M.D.} ROCHESTER, MINN.

Baker, in 1878 , reported a successful implantation of the left ure:er into the bladder by operation through the vagina, for the relief of incontinence due to the opening of the ureter into the anterior wall of the vagina. In 1889, McArthur reported a similar case, in which he operated successfully. Davenport, in 1890, implanted an anomalous ureter by the vaginal route, with good results. In 1894, Bazy reported two instances of ureterovaginal fistula. One patient had an infected hydronephrosis which improved after the implantation of the ureter. Bazy tied a small catheter into the implanted ureter and suggested the use of pelvic lavage with silver nitrate solution, $1: 500$ to $1: 100$, for infection of the kidney. He also mentions two cases of ureterovesical implantation performed by Novaro in 1892. Franz, in 1907, published a report of nine experiments on dogs, with excellent results following ureterovesical implantation; also seventeen clinical cases in which four patients were cystoscoped, and the implanted ureter functioned normally. Krönig, in the same year (1907), reported the cases of nine patients operated on for ureteral fistula, following hysterectomy for cancer. His assistant, Dr. Rauscher, cystoscoped these patients from five months to one and one-fourth years after the implantation. Good function of the kidney was found in five cases; two showed stenosis and slight hydronephrosis. In two cases of bilateral implantation there was hydronephrosis on the left side and good function on the right side in one, and normal function on both sides in the other.

TYPES OF TECHNIC

Coffey, in 1911, published a technic for implanting the ureter or the common duct into the intestine. This

\section{* From the Mayo Clinic.}

* Read before the Section on Genite-Urinary Diseases at the SixtyNinth Annual Session of the American Medical Association, Chicago, June, 1918.

* Because of lack of space, this article is abbreviated in THE JournaL The complete article will appear in the Transactions. of the Section and in the author's reprints. consists of splitting the serous and muscular coats for three fourths of an inch and entering the lumen of the bowel through a small stab wound in the mucosa. The ureter is pulled well into the lumen by means of an anchoring suture placed through the split end of the ureter, and tied three fourths of an inch below its entrance. The serous and muscular layers are then approximated around the ureter, and one stay suture is placed one-fourth inch above the site of the anastomosis (Figs. 1 and 2).

Stiles' technic consists of entering the lumen of the bowel through a stab wound, and approximating the intestinal wall, without further dissection over the ureter. The wall of the ureter is also caught in these sutures. He omits the splitting of the ureter on one side, as well as the stay suture. These methods have been used with slight modifications in our work for implantation into the bladder (Figs. 3 and 4 ).

Furniss has recently published a simple method of ureterovesical anastomosis, consisting of the penetration of a double fold of the bladder wall with an artery forceps, and of the pulling of the severed ureter through both openings made by the forceps. The ureter is secured to the bladder wall by a few interrupted sutures at its lower entrance into the bladder, and the end is permitted to hang free in the cavity of the bladder. The anterior opening is then closed (Figs. 5 and 6).

A technic suggested by Mann of the Mayo Clinic, a report of which has not heretofore been published, has been used in a few of our experiments. Two parallel incisions, onefourth inch in length and one-half inch apart, are made at right angles to the long axis of the bladder, extending down to the mucosa. This seromuscular bridge is undermined, leaving the mucosa intact. A small stab wound is made through the mucosa at the site of the lower transverse incision. The severed ureter, having been split for onefourth inch on its anterior surface and armed with No. 00 catgut, is pulled beneath the bridge from above downward and anchored to the inner surface of the wall of the bladder one-half inch below the opening. One or two interrupted sutures are made on each side of the ureter, approximating the transverse incision up to the ureter. No suture is placed into the ureter except the one put through the flap, for the purpose of securing it to the inner side of the wall of the bladder (Figs. 7 and 8 ).

In making the experimental and clinical observations described in this paper, it has been my purpose to evolve a technic for the reimplantation of the ureter into the bladder, and to study the effect of such operation on the kidney and ureter. Unilateral implantations 
were performed on eighteen dogs and bilateral implantations on three, giving a total of twenty-four observations.

Coffey's technic was used in eight cases. Observations of the end-results were made from one day to five and one-third months after operation. One animal died from peritonitis on the sixth day. The kidney

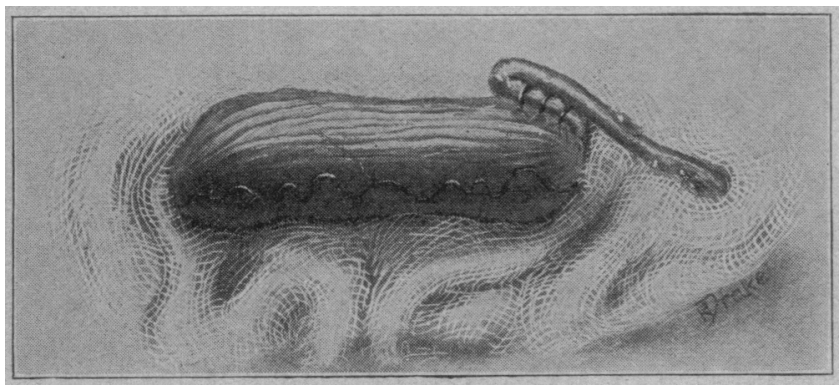

Fig. 2.-Coffey technic completed with bladder everted out of the abdomen.

showed slight hydronephrosis. It was possible to make the ureter leak at the site of anastomosis (Case 1). One death occurred at the end of twenty-four hours. Both ureter and pelvis were dilated, and miliary abscesses were found throughout the kidney. There was also a small localized abscess at the site of the implantation (Case 6). A third animal died from distemper on the tenth day. The pelvis and the ureter both showed a slight hydronephrosis (Case 8 ). Five animals were examined from three weeks to five and one-third months after operation, and showed an entirely normal kidney and ureter. Two observations on the technic were made:

1. In all instances the ureter was implanted on the posterior wall of the bladder a short distance toward the median line of the original insertion, with the bladder pulled well out of the pelvic cavity. It is convenient and natural to embed the ureter from below upward, but when this is done and the bladder is replaced into the pelvis, an acute angulation in the ureter occurs just at the site of the union with the bladder. If the implantation is reversed, that is, from above downward, the ureter will lie in a line with its entrance through the wall of the bladder. In order to have the open side of the ureter facing into the cavity of the bladder, the splitting of the ureter must be done in its anterior wall (Fig. 9).

2. After some observation the last stay suture, placed about one-fourth inch above the site of implantation, was omitted, as the implantation is performed with the bladder empty and in a state of acute contraction. When this viscus becomes distended a great disproportion occurs between this included section of the ureter and portion of the bladder, and the ureter may be acutely kinked and even pulled out of the wall of the bladder, as occurred in one of the cases (Case 11, Fig. 10).

Stiles' technic was carried out in eight cases, with the modification of splitting the anterior aspect of the wall of the ureter for about one-fourth inch. No suture, except the anchoring suture, was permitted to enter the wall of the ureter. Care was taken to avoid any injury to the proximal end of the severed ureter, and no forceps was placed over the end. A forceps was placed on the side of the bladder and the ureter cut with a thin scalpel about $1 \mathrm{~cm}$. above this clamp. While the sutures infolding the ureter in the wall of the bladder were being tied, a thyroid needle was used as a seeker in order to avoid any undue compression on the anastomosis (Fig. 4). There were six complete successes in this group of eight operations. In one case (Case 11) the ureter pulled out of the bladder. Here the additional stay suture had been used. One animal, sacrificed in a physiologic experiment one and one-third months after operation, showed an advanced pyonephrosis (Experiment 12, Fig. 17).

Five operations were done with the technic devised by Mann. Hydronephrosis resulted in one case four months after the operation. In four cases the kidneys and ureters were normal.

Three implantations were done by the method of Furniss, with normal results. One: was a bilateral implantation done at one stage. The placing of a clamp over the proximal end of the ureter was, however, omitted. The small amount of urine leaking from the ureter in such cases will cause no disturbance unless there is previous infection of the kidney, and then a moist pack placed around the ureter will take care of the trouble.

In order to work out the technic, a cystoscopic examination was made under anesthesia in four normal female dogs and in four dogs whose ureters had been implanted. With the animal in the dorsal position, a small speculum was introduced into the vagina and sufficient traction exerted on the labia to bring the urinary meatus into view from its normal location behind the pubic arch. The cystoscope was then quite readily introduced. The ureters were catheterized with No. 4 or No. 5 ureteral catheters in the normal animals. There was obstruction to the catheter in two of the implanted cases; in two others no obstruction occurred.

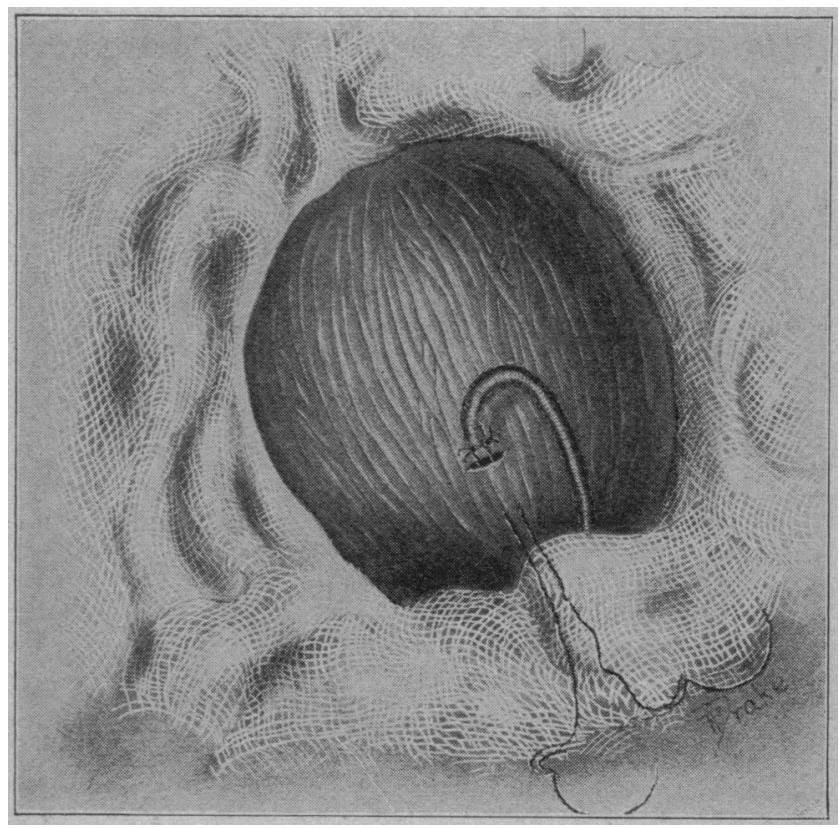

Fig. 3.-Stab wound through which the ureter is pulled within the cavity of the bladder.

In the review of the results of the twenty-four experiments, it was found that there were entirely normal kidneys and ureters in fifteen instances, slight hydronephrosis in two, marked hydronephrosis in one, miliary abscesses of the kidney in one, pyonephrosis in one, normal kidney and hypertrophied ureter in two, 
and the ureter pulled out in two (Tables 1 and 2). Fifteen implantations (62.5 per cent.) were complete successes. Normally functionating kidneys, including two cases with a slight hydronephrosis, were found in nineteen ( 80 per cent.). There was complete failure from stenosis, infection and the pulling out of ureters in five cases ( 20 per cent.).

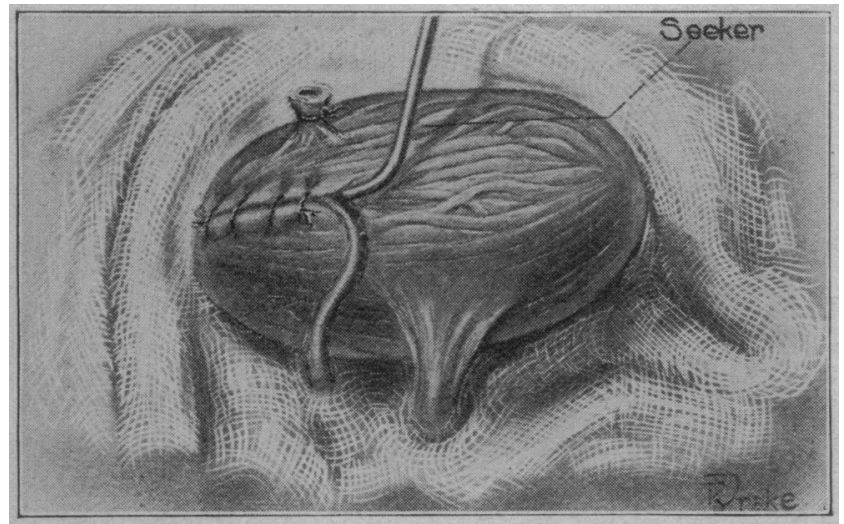

Fig. 4.-Enfolding of the wall of the bladder over the ureter, a seeker being used to avoid compression.

Early in these experiments, fine silk was used for suture material, and in several instances concretions formed around the sutures in the bladder. This did not occur when catgut alone was used.

It is of interest to note that in two cases (Cases 19 and 21) the kidneys were entirely normal, the ureter was hypertrophied and there was no evidence of dilatation. Partial stenosis takes place at the site of the

TABLE 2,-SUMMARY OF DOG CASES

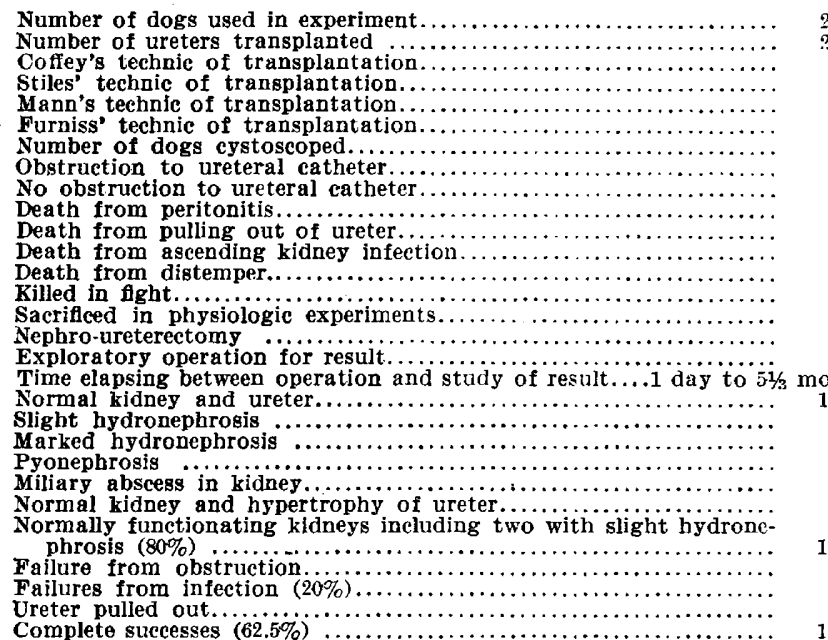

implantation and the muscularis of the ureter undergoes compensatory hypertrophy, consequently dilatation of the pelvis does not occur until this compensation is overbalanced.

Slight dilatation of the pelvis and ureter was found in two cases (Cases 1 and 8), six and ten days respectively after implantation. This was probably owing to edema of the lower end of the ureter and of the wall of the bladder caused by trauma, which subsided in a short time. The utmost care should be taken to minimize trauma during the operation.

In view of the end-results and the simplicity of the operation, the modification of Stiles' technic seems the most suitable in ureterovesical anastomosis. The successful outcome of ureterovesical implantation depends entirely on the technic. This consists of: (1) rigid asepsis to prevent peritonitis and ascending renal infection, (2) a suitable mechanical scheme to establish waterproof anastomosis without causing compression of the ureter, (3) the avoidance of any suture that will enter the wall or lumen of the ureter other than the anchoring suture at its end, and (4) the avoidance of placing any clamp whatever across the extremity of the ureter used in the anastomosis.

\section{CLINICAL REPORT}

In twenty-one cases in the Mayo Clinic, the ureter has been implanted into the bladder and the effect on the kidney has been noted. Fifteen patients had exten-

TABLE 4.-SCMMARY OF RESULTS OF TRANSPLANTATIONS Number of cases cystoscoped following transplantation....... 17 Length of time elapsing between transplantation and cystoseopic examination...........................

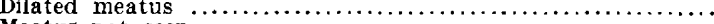
Meatus not seen

Meatus normal contracted

(n)

Contraction of transplanted meatus.

No obstruction to ureteral catheter.

Obstruction to catheter noted...

Infection of specimen from few pus cells to cloudy urine no.ed cormal function, phenolsulphonephthalein and normal pyelogram

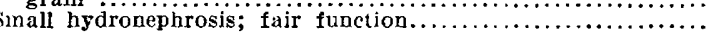
cormal excretion of pair function.....

Functionless kidney

Dilatation

Ureter dion Kidereys showing normal function, $53 \%$; fair function; $18 \%$ functionless, $30 \%$

Deducting Cases 5 , io, 12,15 and $16=$ normal kidneys, $75 \%$; fair functionating kidneys, $25 \%$.

sive resections for tumor of the bladder, and implantation of one ureter; four had ureterovaginal fistula; in one the right ureter opened into the urethra, and in one the left ureter opened into a diverticulum.

The patients who were operated on for malignancy and returned for examination have been longest under

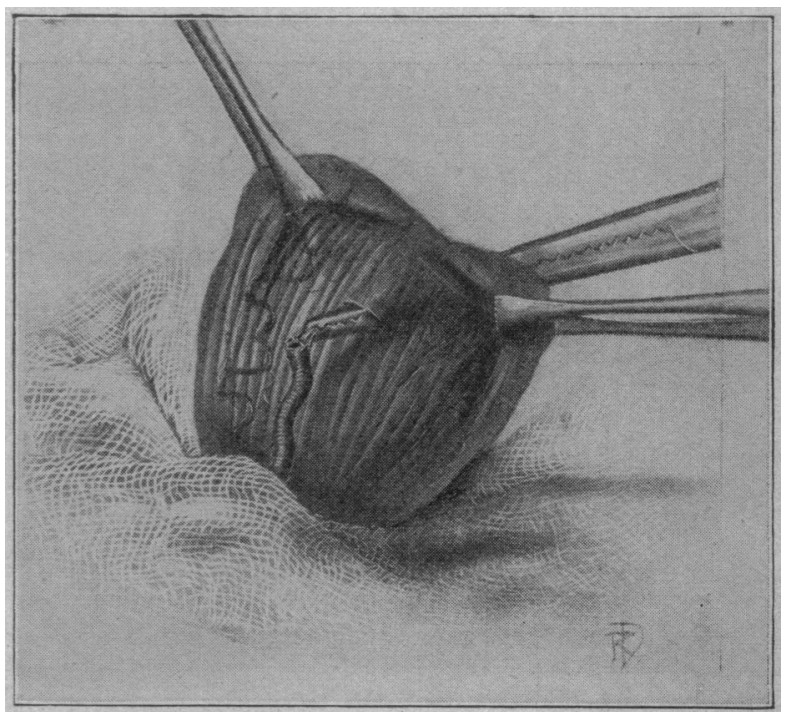

Fig. 5.-The Furniss technic for the implantation of the ureter into the bladder.

observation, three for four years and eight for from three months to one year. When implantation was done for conditions other than tumor of the bladder the time elapsing between the operation and the cystoscopic examination varied from eighteen days to four months. The cystoscopic examination consisted of a 
careful inspection of the entire bladder. The condition of the implanted meatus as to size and contractions and the appearance of the excretion were noted. Whenever feasible, both ureters were catheterized and a differential functional test with phenolsulphonephthalein was done, followed with a pyelogram of the implanted side. In the cases in which the implanted

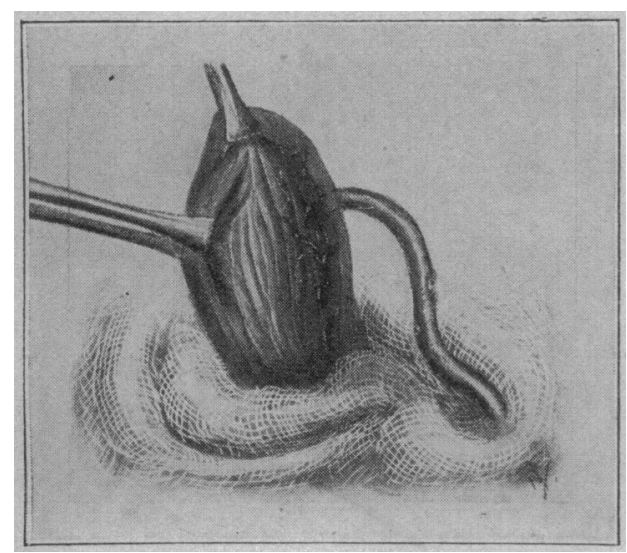

Fig. 6.-The end of the ureter lies free within the cavity of the bladder.

ureter could not be catheterized, a Garceau catheter was passed well up on the normal side, urine from the bladder was taken from the implanted side and a differential test made. When neither side was catheterized, indigocarmin was given intravenously, and the time of its appearance and the intensity of the color as it appeared at the meatus were noted (Tables 3 and 4 ).

Four patients died following resection of carcinoma of the bladder and implantation of one ureter. At necropsy, the cause of death and the result of the implantation were shown (Table 5).

Seventeen of the twenty-one patients were cystoscoped from eighteen days to four and one-half years after operation. The normal output of phenolsulphonephthalein and a normal pyelogram were obtained in five instances ( 30 per cent.) ; the normal phenolsulphonephthalein excretion was obtained in four (23 per cent.), and there was a small hydronephrosis with fair function in three (18 per cent.). Functionless kidneys were found in five instances (30 per cent.). In a review of the histories in the cases of functionless kidneys, two conditions are noted:

1. Marked dilatation of the ureter at the time of the implantation, due to the growth overlying the meatus and causing gradual obstruction in one case (Case 10). In one case (Case 16), in which the right ureter opened into the urethra, there was a dilated ureter.

2. Because of the necessity of resecting a portion of the ureter involved in the malignant growths, where there was very dense scar tissue in ureteral fistulas, the implantation was performed with considerable tension on the ureter (Cases 12 and 15).

In nine cases (53 per cent.) of the seventeen patients, the function of the kidney was entirely normal. There was fair function in three cases (18 per cent.), and functionless kidneys in five cases (30 per cent.). If we deduct those cases in which marked dilatation was noted at the time of operation, and in which the ureters were implanted under tension, normal kidney function occurred in 75 per cent. and fair function in 25 per cent.
Of the four patients who died from the fourth day to the second month after the operation, two showed slight dilatation on the implanted side ; in one the pelvis was dilated to three times the normal size, and in one there was no evidence of obstruction.

In view of the fact that functionless kidneys result when the implantations are done with widely dilated ureters, and when it is necessary to put the ureter on tension in order to accomplish the anastomosis, in such cases ligation of the ureter is preferable to implantation.

If, on cystoscopic examination, a tumor of the bladder, which appears malignant, is found overlying one or the other meatus, or in close proximity to it, the opposite ureter should be catheterized to ascertain the functional capacity of the kidney. If, at the time of the operation, a widely dilated ureter is found, or if tension is necessary, the surgeon has definite information regarding the ability of the opposite kidney to carry on the urinary elimination. If , on account of hematuria, spasm of the bladder, spasm or anatomic obstruction, the opposite ureter cannot be catheterized, a combined phenolsulphonephthalein test should be done. If the combined output is normal, or nearly normal, and a widely dilated ureter is found, it is safe to assume that the normal phenolsulphonephthalein output is from the opposite side, and ligation of the ureter may be safely done.

In all cases in. which advanced pathologic changes of the kidney and ureter have not occurred prior to surgical relief, and in which tension can be avoided,

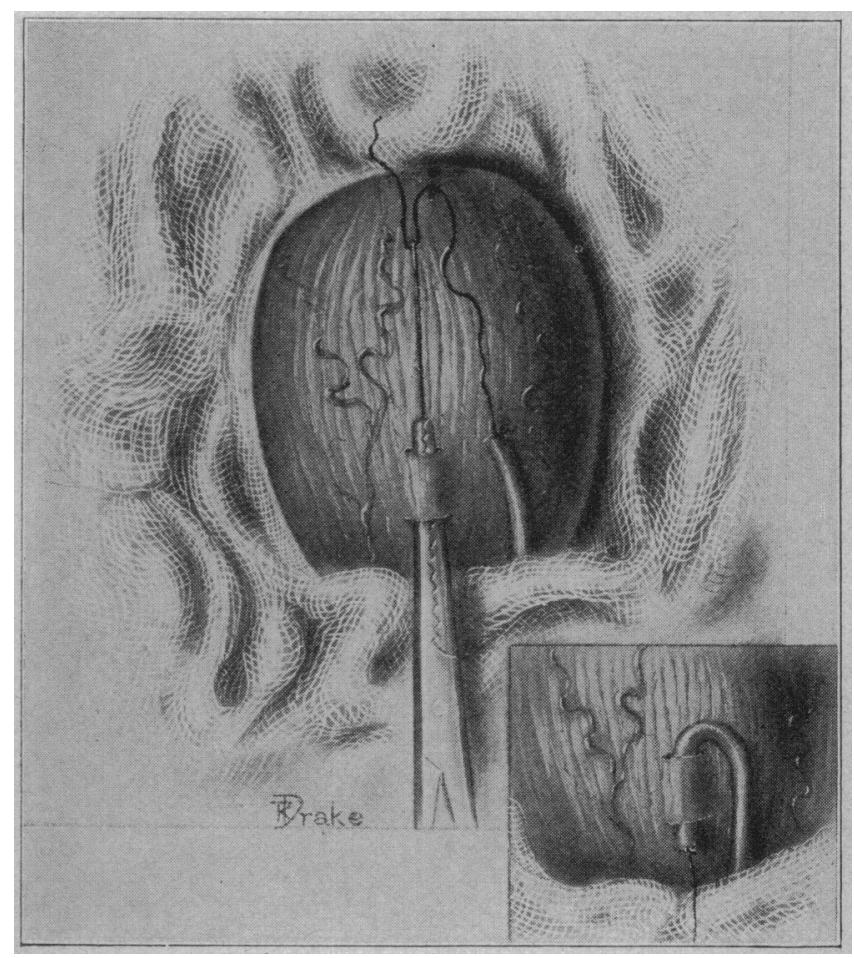

Fig. 7.-Mann's technic for implanting the ureter into the bladder. Fig. 7.-Mann's technic for implanting the ureter itlto the bladder.
A seromuscular bridge is undermined and the ureter is pulled beneatl A seromuscular bridge is underming
this bridge from above downward.

the reimplantation of the ureter into the bladder should be done.

\section{CONCLUSIONS}

1. From experimental and clinical observations, it is obvious that a normal or almost normal kidney and ureter should result following the implantation of the ureter into the bladder. 
2. The utmost care to minimize the operative trauma must be observed.

3. The placing of a forceps over the end of the uterer should be avoided.

4. No suture should enter the wall or lumen of the uterer other than the anchoring suture placed in the split extremity of the ureter; and the approximation

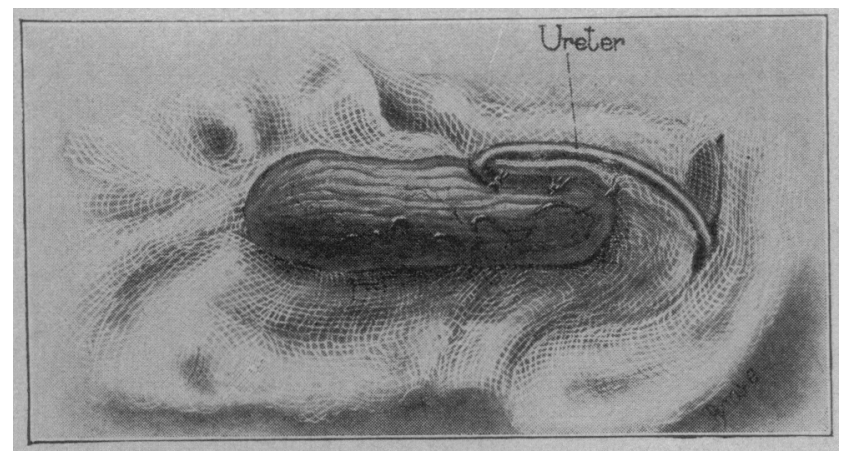

Fig. 8.-Mann's technic of implantation completed, showing the bladder empty and pulled well out of the abdomen.

of the wall of the bladder must be accomplished without undue compression.

5. When marked dilatation of the ureter has occurred prior to surgical interference, and when it is necessary to implant the ureter under tension, a successful result is very doubtful and ligation is preferable to any effort of implantation.

\section{REPORT OF CASES}

CASE 1 (No. 80914).-A woman, aged 40, was admitted to the clinic, March 4, 1913. A diagnosis was made of a broad, flat carcinoma extending over the base of the bladder and into the urethra. Aug. 6, 1913, excision and cautery of the base of the tumor and implantation of the right ureter was done. The patient returned each year for cystoscopic examination. There was no recurrence except a persistent caruncle of the urethra, which was cauterized. Microscopic examination showed it to be inflammatory. Oct. 26, 1917, four and one-fourth years after the resection of the growth, the left ureter was catheterized. The differential functional phenolsulphonephthalein test showed 15 per cent. from the ureter, and 17.5 per cent..from the bladder specimen in fifteen minutes after intravenous injection. Nov. 30, 1917, the right ureter was catheterized easily, and clear urine flowed normally through the catheter. A pyelogram made on this date showed no dilatation of the pelvis (Fig. 23). The patient is in good general condition.

CASE 2 (No. 86197).-A woman, aged 50, was admitted to the clinic, June 18, 1913. A diagnosis of malignant papilloma of the base of the bladder was made. June 25, 1913, suprapubic resection of the right quadrant and floor of the bladder with implantation of the right ureter was done. Cystoscopic examination in 1914, 1915, 1916, and 1917 showed no evidence of recurrence. Feb. 8, 1918, four years and seven and onehalf months after the removal of the tumor, a dilated right meatus was found. The catheter could not be passed up the ureter. The left ureter was catheterized with a Garceau catheter. The intravenous phenolsulphonephthalein test showed 20 per cent. in the ureter, and 15 per cent. in the bladder in fifteen minutes. The patient's general health is good.

CASE 3 (No. 100111).-A man, aged 53, was admitted to the clinic, Feb. 4, 1914. A suprapubic resection of a tumor of the bladder had been done elsewhere, about six months previous to admission. A recurring tumor of the bladder was found, and, Feb. 7, 1914, resection and cautery of one half of the bladder with implantation of the right ureter was done. Nov. 5, 1914, cautery of the bladder for recurrence was again necessary. Cystoscopic examinations in 1915, 1916 and 1917 showed a small recurring growth at the site of the operation scar, which was fulgurated. Examination, December 4, 1917, showed a small reddened area in the old scar but no evidence of recurrence. The right ureter opening was widely dilated, and frequent spurts of urine came from the meatus. The secretion from the right ureter showed a few pus cells. The phenolsulphonephthalein test showed 4 per cent. in the right ureter, and 5 per cent. in the left in fifteen minutes. A pyelogram of the right kidney showed a small hydronephrosis. The patient is now in excellent health (Fig. 24).

CASE 4 (No. 163712).-A man, aged 69, was admitted to the clinic, June 23, 1916. A diagnosis was made of a papilloma of the bladder the size of a hen's egg, lying in the right base. July 11, 1916, excision of the tumor and implantation of the right ureter was done. Papillary epithelioma was diagnosed pathologically. A cystoscopic examination, Oct. 27, 1917, one year and three and one-half months after operation showed no recurrence. The catheter passed easily up the right ureter and negative urine was collected. Phenolsulphonephthalein output showed 15 per cent. in the right ureter, and 17.5 per cent, in the bladder. The pyelogram showed the right kidney to be normal. The general condition of the patient was good (Fig. 25).

CASE 5 (No. 185582).-A woman, aged 60, was admitted to the clinic, Feb. 13, 1917, and a diagnosis of carcinoma of the bladder was made. March 21, 1917, a suprapubic excision of one third of the wall of the bladder was done. One inch of the right ureter was removed and the left ureter was implanted into the base of the bladder. It was not possible satisfactorily to reconstruct the bladder. The involved portion of the urethra was removed also. Jan. 22, 1918, ten months after the operation, there was no evidence of recurrence of the tumor. The left meatus could not be seen; the right was normal. A catheter was passed well up the right ureter. The phenolsulphonephthalein output showed 12 per cent. in the right ureter, and a trace in the bladder in fifteen minutes. The left kidney was found to be functionless probably because of the tension on the ureter necessary for its implantation.

CASE 6 (No. 69825).-A man, aged 54, was admitted to the clinic, June 27,1912 . A carcinoma of the left base and wall of the bladder was found. July 6,1912, suprapubic resection of one third of the bladder with cautery of the base, and implantation of the left ureter was done. Cystoscopic examination, March 8, 1913, showed no evidence of recurrence. The left meatus spurted urine normally. In answer to an inquiry in August, 1916, the patient stated that he was in good health and had no urinary inconvenience.

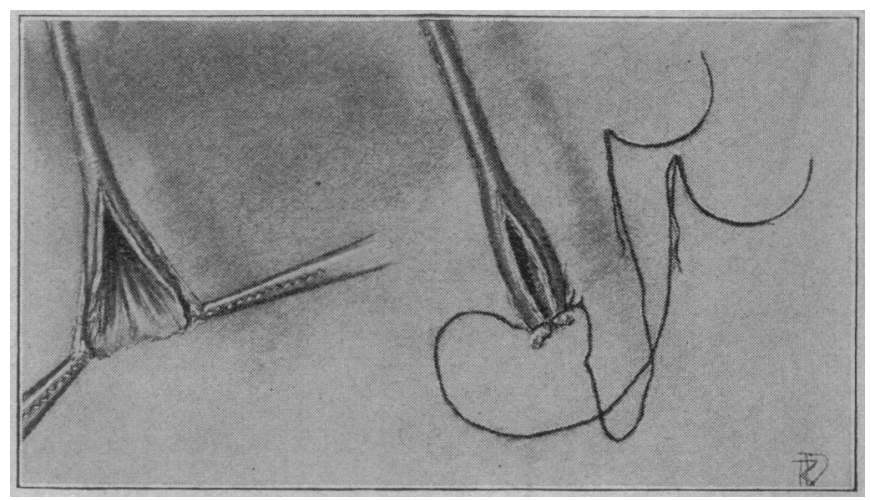

Fig. 9.- Preparation of the ureter for implantation into the bladder. Anterior wall split trom one-fourth to one-half inch and anchoring
sutures introduced.

CASE 7 (No. 186610).-A man, aged 54, was admitted to the clinic, Feb. 23, 1917. March 9, 1917, a suprapubic resection of one third of the left wall of the bladder and one-half inch of the left ureter, with implantation of the ureter was done for carcinoma. Oct. 18,1917, cystoscopic examination showed no recurrence. The left meatus was widely open and spurted urine normally. A catheter passed easily and the specimen of urine showed a few pus cells. Intravenous phenolsul- 
phonephthalein appeared in four minutes, from the left ureter 4 per cent. and from the bladder 20 per cent. The catheter drained poorly. The pyelogram showed a normal kidney and ureter (Fig. 26). The patient's health is good.

CAsE 8 (No. 213632).-A man, aged 48, was admitted to the clinic, Nov. 20, 1917. A suprapubic excision with cautery was done at the base of the left wall of the bladder, and base of the left ureter for multiple papilloma. One large growth of the size of an orange was situated at the left meatus. Cystoscopic examination four months and twenty-two days after the operation showed no evidence of recurrence. The left meatus, which was located high up on the left wall of the bladder, was catheterized easily. Indigocarmin, dark blue in color, appeared in five minutes on both sides. The pyeloureterogram showed a normal pelvis and ureter throughout. Examination of urine from the left kidney was negative (Fig. 27). The patient has gained 8 pounds in weight and has no urinary inconvenience.

CASe 9 (No. 213837.-A man, aged 42, was admitted to the clinic, Nov. 11, 1917. A diagnosis of a large tumor of the bladder and marked secondary anemia was made. The hemoglobin was 37 per cent. A transfusion of 500 c.c. of blood was given eleven days before operation. Nov. 24, 1917, a suprapubic resection of the left one third of the bladder, extending the dissection close to the right ureter, was done. The left ureter was implanted and a small rubber catheter was inserted into it for a short distance, and brought out through the suprapubic wound. March 22, 1918, four months after the operation, the patient returned for cystoscopic observation. There was no recurrence. The capacity of the bladder was 4 ounces. The left ureter had probably been implanted in the dome. It was gaping, and no excretion was seen. A catheter could not be passed. The right meatus, which was normal, was catheterized. Phenolsulphonephthalein showed 25 per cent. in the right ureter, and 2 per cent. in the bladder in fifteen minutes. The left kidney was functionless. The patient's general condition was much better. The hemoglobin was 58 per cent.

CASE 10 (No. 213710).-A man, aged 59, was admitted to the clinic, Nov. 13,1917 . November 24 , resection of one third of the bladder, right wall and base, including two-thirds of an inch of the right ureter, with implantation of the right ureter was done. A small catheter was passed four inches up into the implanted ureter. The ureter was dilated considerably, apparently from obstruction, the result of the growth. Cystoscopic examination March 21, 1918, nearly four months after the resection, showed no recurrence. The right meatus was gaping. Contractions were absent and the left meatus was normal. Indigocarmin injected intravenously appeared from the left side in three minutes, dark blue in color. None was seen from the right meatus in fifteen minutes. The catheter could not be passed up the implanted ureter. The right kidney was functionless.

CASE 11 (No. 204790).-A woman, aged 56, was admitted to the clinic, Aug. 15, 1917. The patient had complained of frequency of urination and hematuria for two months. Aug. 22, 1917 , a suprapubic resection of one half the bladder and part of the vaginal wall with implantation of the left ureter was done. A diagnosis of epithelioma was made pathologically. Nov. 24, 1917, three months after the operation, there was no recurrence. The left meatus was not seen because of the deformity of the bladder. A Garceau catheter was passed into the right ureter. The phenolsulphonephthalein test showed 12.5 per cent. in the right ureter, and 17.5 per cent. in the bladder in fifteen minutes. The patient's general health is much improved.

CASE 12 (No. 221950).-A woman, aged 33, was admitted to the clinic, Feb. 14, 1918. Following vaginal drainage for pelvic abscess, three years prior to admission, the patient developed incontinence. A left ureterovaginal fistula was found. Feb. 26, 1918, the lower eight inches of the left ureter was dissected out of very dense scar tissue and was reimplanted ander tension. A small catheter was introduced into the implanted ureter and brought out through the urethra. A cystoscopic examination a month later showed granulation tissue in the left dome. No spurts of urine were seen from the left side. A Garceau catheter was passed into the right ureter, and the differential functional test showed 20 per cent. in the right ureter, and none in the bladder. The left kidney was functionless because of cicatricial contraction at the lower end of the left ureter.

CAse 13 (No. 214196).-A woman, aged 23, was admitted to the clinic, Nov. 17, 1917. Following instrumental delivery fourteen months previously, the patient had developed incontinence. A diagnosis of left ureterovaginal fistula and right uretero-uterine fistula was made. The left ureter was implanted, Dec. 3, 1917, and the right was implanted, Dec. 22, 1917. A cystoscopic examination seven weeks after the first operation showed the left meatus to be normal. Indigocarmin appeared in five minutes, dark blue in color. A No. 6 catheter was passed easily. The pyelogram showed normal outline. A specimen of the urine contained a large number of pus cells. Inflamnatory reaction obscured the right meatus. There was a $\mathrm{s} \mathrm{m}$ a 11 uretero-abdominal postoperative fistula on the right (Fig. 28).

Case 14 (No. 102891).-A woman, aged 41 , was admitted to the clinic, March 24, 1914. The patient had developed a left ureterovaginal fistula following operation for cancer of the uterus five months previously. An implantation of the left ureter was done, April 7, 1914. Eighteen days later, a ureteral catheter was passed easily, and cloudy urine, showing numerous pus cells, flowed rapidly for twenty minutes. Two ounces of urine were withdrawn, the specific gravity being 1.001 . Before implantation could be accomplished, the lower end of the ureter had to be dissected out of dense scar tissue.

CASE 15 (No. 144658).-A woman, aged 42, was admitted to the clinic, Oct. 30, 1915. The patient had developed a right ureterovaginal fistula following hysterectomy done at the clinic. March 15, 1916, the right ureter was dissected free from the scar tissue and implanted into the bladder. A cystoscopic examination twenty days after the operation showed the end of the right ureter protruding into the bladder. It was not possible to catheterize on account of the obstruction. The left kidney was catheterized, and the differential functional test showed 13 per cent. in the left ureter, and 2 per cent. in the bladder in thirty minutes.

CASE 16 (No. 163923).-A woman, aged 21, was admitted to the clinic, June 27,1916 . The patient had suffered from incontinence since childhood. The right ureter was found opening into the urethra. Implantation of a widely dilated right ureter was done, April 25, 1917. The cystoscopic examination four months later showed an infected hydronephrosis con- 
taining more than 2 ounces of cloudy urine. The phenolsulphonephthalein output showed 15 per cent. in the right ureter and 30 per cent. in the bladder in fifteen minutes.

CASE 17 (No. 215976).-A man, aged 32, was admitted to the clinic, Dec. 7, 1917. An operation for diverticulum of the bladder was done, Feb. 26, 1918. The left ureter was found opening into this pouch and was transplanted. On cystoscopic examination six weeks later, it was impossible to get a satisfactory view of the transplanted meatus. A No. 6 catheter was passed into the right ureter and a differential functional test done which showed 25 per cent. from the right ureter, and 12 per cent. from the bladder.

CASE 18 (No. 210877).-A man, aged 54, was admitted to the clinic, Oct. 15, 1917. Nov. 16,1917, a suprapubic resection of one half of the bladder with implantation of the left ureter was done for cancer. The patient died in the hospital on the fourth day after the operation. Necropsy showed advanced myocardial changes and pulmonary edema. There were multiple small cortical abscesses in the left kidney and a slight hydronephrosis. The ureter was contracted at the site of the anastomosis and was dilated above this point (Fig. 29).

CASE 19 (No. 218877).-A man, aged 60, was admitted to the clinic, Jan. 12, 1918. Jan. 19, 1918, a suprapubic resection of the bladder and one and one-half inches of the right ureter, with reimplantation into the dome of the remaining portion of the bladder, was done for extensive cancer. A small catheter was passed into the implanted ureter and brought out through the suprapubic wound. The patient died on the twelfth day from bilateral pulmonary emboli. There was no obstruction at the site of implantation. Both kidneys showed arteriosclerotic changes with slight dilatation of the right kidney pelvis (Fig. 30 ).

CASE 20 (No 101710).-A man, aged 45, was admitted to the clinic, Mar. 11, 1914. A part of the right wall and base of the bladder was excised, Dec. 14, 1917, with implantation of the right ureter into the base, for early epithelioma of the bladder. A small catheter was passed into the implanted ureter. The convalescence was uneventful for one month, when abdominal distention and coma developed, and the patient died. Necropsy showed a general peritonitis, with firm union of the implanted ureter and an old perivesical hematoma near the site of implantation (Fig 31).

CASE 21 (No. 219087). -A man, aged 40, was admitted to the clinic, Jan. 14, 1918. Jan. 22, 1918, a resection of the base and the right one half of the bladder, with transplantation of the right ureter into the dome was done for extensive cancer. The ureter was dilated to the size of a finger. A catheter was passed into the ureter. The cancer had extended into the perivesical fat. The patient died two months after the operation. Necropsy showed a large bilateral psoas abscess, extensive metastasis to the liver, and carcinomatous extension into the perivesical area with marked sloughing of tissues. The site of anastomosis could not be made out, on account of the necrosis of the bladder, and the surrounding infiltration. There was marked bilateral dilatation of the ureters and kidneys (Fig. 32).

\section{ABSTRACT OF DISCUSSION}

DR. V. D. Lespinasse, Chicago: The specimen that interested me most was the one which showed a dilatation of the ureter without dilatation of the kidney pelvis. In my work with dilatation of the ureter for the removal of stone, we found that when the ureter is obstructed a dilatation begins at that point and travels toward the kidney pelvis. These specimens show this phenomenon beautifully, and one in particular with a slight cicatricial contraction and consequent partial obstruction shows the dilatation progressing up to the kidney. The dilatation had just started to involve the kidney when the animal was sacrificed.

Dr. Arthur L. Chute, Boston: I would like to call attention to two things. One is a sort of rough and ready method of replanting or transplanting the ureter which I have used in quite a number of dogs. I introduce from below in either a man or a woman a long uro-catheter of size 12, making a little hole in the bladder anywhere that I can do it, and after I have slipped the ureter up 3 or 4 c.c., I then push the whole thing back into the bladder, and insert one or two stay sutures wherever I can get them. While it is not a very attractive technic it brings the result. I have not had any opportunity of catheterizing human ureters in that way, but on dogs it seems to be a very feasible method. At the same time, with a retention catheter you keep the bladder open and prevent the possibility of pulling out, while it does not add very much to the extent of the operation.

Dr. Charles M. McKenna, Chicago: I can see from Dr. Peterson's slides that surgical repair is the important point which he intended to bring out. Too much cannot be said about surgical repair, either in genito-urinary surgery, or in general surgery. I do not quite understand why Dr. Peterson makes a second incision in the bladder to do the transplant. I should like to ask Dr. Peterson why it is not a good plan to transplant the ureter in the upper angle of the original incision. There will be less scar tissue to deal with there than there will by making a new opening, and less danger of infection since you have only one incision. I have used this latter method in my own cases and am satisfied with the result.

Dr. Bernard ERdman, Indianapolis: What method of transplantation was used in the case of the bladder with one ureter, and one ureter transplanted into the bowel?

Dr. Anders Peterson: The Coffey technic was used for the bowel implantation and the Stiles technic for the implantation into the bladder.

Dr. F. C. Herrick, Cleveland: I think in the anastomoses which possibly may be in question, and also in preventing possible stricture from the swelling, a catheter is of very great value to be left in for from five to eight days-possibly seven days-and then bring it out. It comes out very readily, of course. Some use a solid bougie.

Dr. Anders Peterson, Rochester, Minn.: Dr. Chute has repeatedly placed in the ureters a small rubber catheter large enough to completely fill the ureter. It is brought out through the suprapubic wound that is used as drainage after the section, and drains the urine quite freely. We believe it is a good thing to do; but in animal experiments, of course, it is not feasible, and it does not seem to be necessary, since results may be obtained by careful methods of suturing. In man there is danger of stricture.

In answer to Dr. McKenna's question in regard to making the anastomosis in the upper angle of the incision. This can, and very often has been done. In operating on the bladder large resections have to be made. The method used is not of such great importance, but all efforts must be made not to damage the upper section of the ureter which you are going to use. The ureter does not stand manipulation. If that is borne in mind, I believe results may be obtained without catheters.

Pellagra.-Figures covering the death rate for pellagra in the United States among the policy holders of the Metropolitan Life Insurance Company showed a gratifying decrease during 1916. In 1911, according to a bulletin issued by the company, there were 277 deaths among its policyholders from pellagra; in 1915 the number had increased to 650 , and the rate had increased from 3.6 per hundred thousand exposed persons to 6.7 . In 1916 the deaths fell to 368 , and the rate to 3.6 as in 1911, a drop of 46 per cent. in 1916 as compared with 1915. This drop was observed in many districts of the South where the company does business. It is suggested that the drop in the death rate from this disease coinciding with the greater prosperity of the agricultural portion of the South during the high prices incident to the war in a way confirms the tentative conclusion of some of the government experts that pellagra is a "deficiency" disease induced by insufficient, poorly balanced dietaries rather than an infectious disease. The statistics of the company further show that the disease is more prevalent among the colored than the white people, and more frequent in women than in men. It is also indicated that the incidence of the disease increases with age. 